\title{
The Argument from Design: A Guided Tour of William Paley's Natural Theology (1802)
}

\author{
T. Ryan Gregory
}

Published online: 24 October 2009

(C) Springer Science + Business Media, LLC 2009

\begin{abstract}
According to the classic "argument from design," observations of complex functionality in nature can be taken to imply the action of a supernatural designer, just as the purposeful construction of human artifacts reveals the hand of the artificer. The argument from design has been in use for millennia, but it is most commonly associated with the nineteenth century English theologian William Paley and his 1802 treatise Natural Theology, or Evidence of the Existence and Attributes of the Deity, Collected from the Appearances of Nature. The book remains relevant more than 200 years after it was written, in large part because arguments very similar to Paley's underlie current challenges to the teaching of evolution (indeed, his name arises with considerable frequency in associated discussions). This paper provides an accessible overview of the arguments presented by Paley in Natural Theology and considers them both in their own terms and in the context of contemporary issues.
\end{abstract}

Keywords Adaptation · Chance - Design · Evolution · Eye . Teleological argument

I did not at that time [as a Cambridge theology student, 1827-1831] trouble myself about Paley's premises; and taking these on trust, I was charmed and convinced by the long line of argumentation. (p. 59)

The old argument from design in nature, as given by Paley, which formerly seemed to me so conclusive, fails, now that the law of natural selection has been discovered. (p. 87)

Charles Darwin, Autobiography

T. R. Gregory $(\bowtie)$

Department of Integrative Biology, University of Guelph, Guelph, ON N1G 2W1, Canada

e-mail: rgregory@uoguelph.ca

\section{Introduction}

The "teleological argument," better known as the "argument from design," is the claim that the appearance of "design" in nature - such as the complexity, order, purposefulness, and functionality of living organisms - can only be explained by the existence of a "designer" (typically of the supernatural variety). In its most familiar manifestation, the argument from design involves drawing parallels between humandesigned objects (e.g., telescopes, outboard motors) and biological counterparts with similar functional roles (e.g., eyes, bacterial flagella). The former are complex, often indivisibly so if they are to maintain their current function, clearly perform specific functions, and are known to have been the product of intentional design. The functional complexity of living organisms is far greater still, it is argued, and, therefore, must present even stronger evidence for the role of intelligent agency.

Though the basic premise of the teleological argument had been articulated by thinkers as far back as ancient Greece and Rome, today it is almost universally associated with the writings of one person: William Paley (Fig. 1). Paley was born in July 1743 in Peterborough, Cambridgeshire, England. He was educated at Christ's College, Cambridge, and was ordained a deacon in 1766 and soon thereafter a priest in Cambridge. He was appointed Archdeacon of Carlisle Cathedral in 1782 and awarded a Doctor of Divinity degree at Cambridge in 1795. He authored several successful theological works, the best-known being Natural Theology, or Evidence of the Existence and Attributes of the Deity, Collected from the Appearances of Nature.

Natural Theology was published in 1802, only three years before Paley's death on May 25, 1805. It was very successful, going through ten editions in the first four years alone (see Fyfe 2002). Despite being written in 


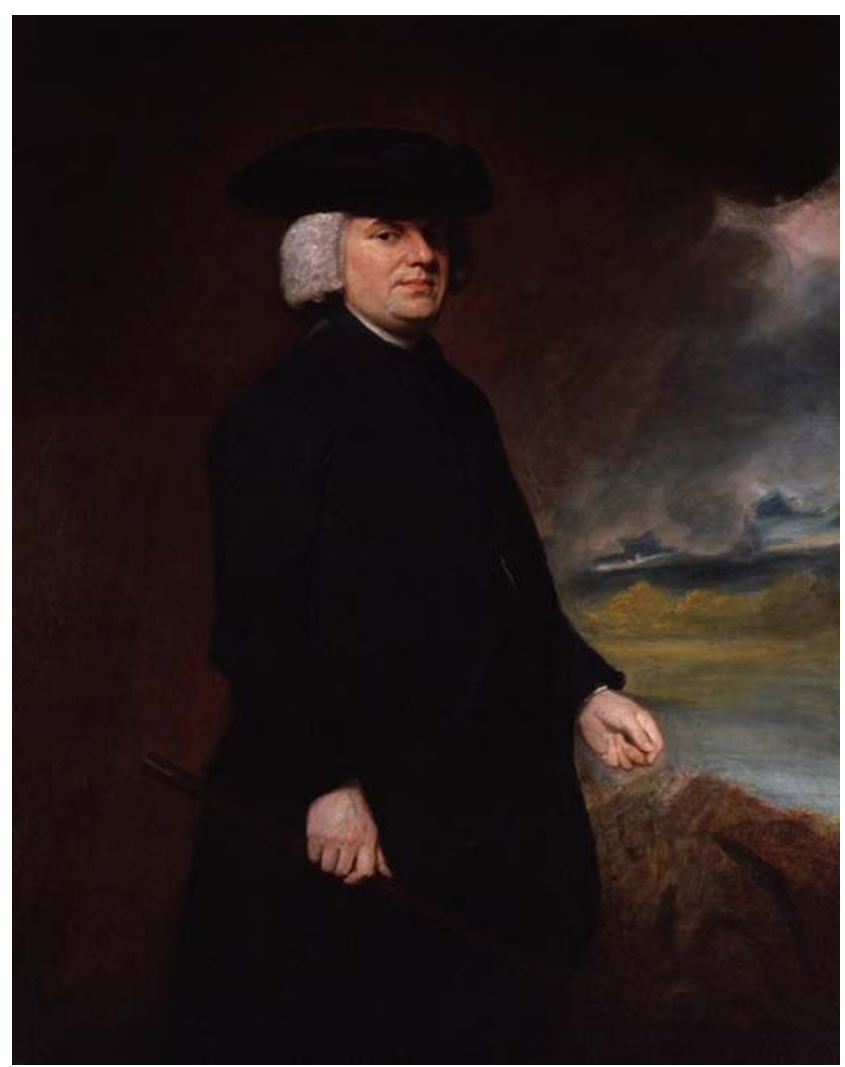

Fig. 1 William Paley (1743-1805). Portrait circa 1790 by George Romney (National Portrait Gallery, London)

labyrinthine prose (by modern standards), Natural Theology remains an especially lucid exposition of the classic argument from design. This undoubtedly is one of the reasons that Paley's name is most commonly linked with the design argument even though it was by no means original to him. ${ }^{1}$

Darwin was influenced by Paley's work, and some modern authors have cited it as an important example of pre-Darwinian "adaptationist" thinking (e.g., Dawkins 1986; Williams 1992; but see Gliboff 2000; McLaughlin 2008). Whatever its significance in the past, it is clear that Paley's contribution continues to be of direct relevance in the current educational and political climate. Notably, Natural Theology was exhibit P-751 in the landmark 2005 Kitzmiller v. Dover trial, which successfully challenged the constitutionality of promoting "intelligent design" in US public schools. Paley's name appears more than 80 times in

\footnotetext{
1 John Ray's 1691 treatise The Wisdom of God Manifested in the Works of the Creation was a notable forerunner (available online: http://books.google.ca/books?id=HvQ4AAAAMAAJ).
}

the trial testimony transcripts, and he is mentioned a further half a dozen times in Judge Jones's decision. ${ }^{2}$

In light of their continuing importance in current discourse, it is worth exploring the arguments presented in Paley's classic treatise. This review is intended to provide a "guided tour" of Natural Theology, ${ }^{3}$ giving the reader an abridged and annotated rendition of Paley's widely referenced (but less often read) account of the argument from design.

\section{Watches and Watchmakers}

Natural Theology opens with the paragraph for which it is best (if not exclusively) known, in which Paley draws a contrast between a rock and a pocket watch: ${ }^{4}$

In crossing a heath, suppose I pitched my foot against a stone, and were asked how the stone came to be there; I might possibly answer, that, for any thing I knew to the contrary, it had lain there for ever: nor would it perhaps be very easy to show the absurdity of this answer. But suppose I had found a watch upon the ground, and it should be inquired how the watch happened to be in that place; I should hardly think of the answer which I had before given, that, for any thing I knew, the watch might have always been there. Yet why should not this answer serve for the watch as well as for the stone? why is it not as admissible in the second case, as in the first? For this reason, and for no other, viz. that, when we come to inspect the watch, we perceive (what we could not discover in the stone) that its several parts are framed and put together for a purpose, e. $g$. that they are so formed and adjusted as to produce motion, and that motion so regulated as to point out the hour of the day; that, if the different parts had been differently shaped from

\footnotetext{
${ }^{2}$ Online copies are available for both the transcripts (http://ncseweb. org/creationism/legal/kitzmiller-trial-transcripts) and the decision (http://www.pamd.uscourts.gov/kitzmiller/kitzmiller_342.pdf).

${ }^{3}$ The first edition of Natural Theology of 1802 is available in the Oxford World's Classics series from Oxford University Press. Quotes and associated page numbers given in this review come from the 12th edition, as provided by The Complete Work of Charles Darwin Online (http://darwin-online.org.uk/content/frameset?itemID=A142). A later edition is also available at Google Books (http://books.google.com/ books?id=-XFHAAAAIAAJ). The differences between editions are minor.

${ }^{4}$ Like many of the arguments most famously attributed to Paley, an analogy to a timepiece was used by various thinkers before him. For example, Marcus Tullius Cicero wrote in his De Natura Deorum in 45 BCE: "When you see a sundial or a waterclock, you see that it tells the time by design and not by chance. How then can you imagine that the universe as a whole is devoid of purpose and intelligence, when it embraces everything, including these artifacts themselves and their artificers?" Numerous other examples are reviewed by Moore (2009).
} 
what they are, of a different size from what they are, or placed after any other manner, or in any other order, than that in which they are placed, either no motion at all would have been carried on in the machine, or none which would have answered the use that is now served by it. (p.1-2)

Thus, in the very first passage of a book written more than two centuries ago, Paley encapsulates the core components of the argument from design - an argument that has been revived in much the same form by proponents of "intelligent design." Specifically, Paley points out that the watch exhibits an irreducibly complex organization that was obviously constructed to perform a specific function. Remove or rearrange any of its intricate inner workings, and the watch becomes barely more effective at keeping time than the rock formerly dismissed with a kick. ${ }^{5}$ From this, Paley concludes that

...the inference, we think, is inevitable, that the watch must have had a maker: that there must have existed, at some time, and at some place or other, an artificer or artificers who formed it for the purpose which we find it actually to answer; who comprehended its construction, and designed its use. (p.3)

Furthermore, like modern proponents of the argument from design, Paley argues that one need not know any details of the designer's identity or methods to conclude that an intelligent agent was involved:

Nor would it, I apprehend, weaken the conclusion, that we had never seen a watch made; that we had never known an artist capable of making one; that we were altogether incapable of executing such a piece of workmanship ourselves, or of understanding in what manner it was performed; all this being no more than what is true of some exquisite remains of ancient art, of some lost arts, and, to the generality of mankind, of the more curious productions of modern manufacture. (p.3-4)

Today's neo-Paleyans must also concur with Paley that the watch's delicate functionality could not be the product of chance, inherent "principles of order," or laws of matter, nor merely an illusion of design. For Paley, this conclusion supersedes all other considerations and renders additional details largely superfluous. As he wrote,

Neither...would our observer be driven out of his conclusion, or from his confidence in its truth, by being told that he knew nothing at all about the matter. He knows enough for his argument: he knows

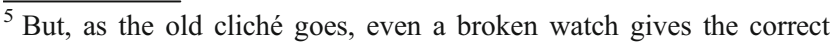
time twice per day.
}

the utility of the end: he knows the subserviency and adaptation of the means to the end. These points being known, his ignorance of other points, his doubts concerning other points, affect not the certainty of his reasoning. The consciousness of knowing little, need not beget a distrust of that which he does know. ${ }^{6}$ (p.7)

However, given their aggressive resistance to the notion of suboptimality or nonfunction of biological structures, ${ }^{7}$ it appears that many modern design proponents disagree with Paley's subsequent assertions that neither imperfections nor ambiguous - or even nonexistent-functions refute the thesis of design for the origin of complex, (mostly) functional objects or organs. In this sense, Paley could be said to adhere more closely to the analogy with human artifacts than do many of his present-day counterparts:

Neither, secondly, would it invalidate our conclusion, that the watch sometimes went wrong, or that it seldom went exactly right. The purpose of the machinery, the design, and the designer, might be evident, and in the case supposed would be evident, in whatever way we accounted for the irregularity of the movement, or whether we could account for it or not. It is not necessary that a machine be perfect, in order to show with what design it was made: still less necessary, where the only question is, whether it were made with any design at all. (p.4-5)

Nor, thirdly, would it bring any uncertainty into the argument, if there were a few parts of the watch, concerning which we could not discover, or had not yet discovered, in what manner they conduced to the general effect; or even some parts, concerning which we could not ascertain, whether they conduced to that effect in any manner whatever. For...if by the loss, or disorder, or decay of the parts in question, the movement of the watch were found in fact to be stopped, or disturbed, or retarded, no doubt would remain in our minds as to the utility or intention of these parts, although we should be unable to investigate the manner according to which, or the connexion by which, the ultimate effect depended

\footnotetext{
${ }^{6}$ For Paley, biochemistry represented a particularly impenetrable frontier that reinforced the existence of a designer with a more thorough knowledge of chemistry (pp.83-91). For their part, modern design proponents tend to focus on subcellular and molecular features whose origins have only recently become amenable to investigation. ${ }^{7}$ A prime example is provided by so-called junk DNA. A common myth, repeatedly invoked by anti-evolutionists, science writers, and misinformed biologists alike, asserts that potential functions for nongenic components of the genome were long dismissed by mainstream science. Reference to the scientific literature from the relevant time period thoroughly undermines this claim (http://genomicron.blogspot. com/2008/02/junk-dna-quotes-of-interest-series.html).
} 
upon their action or assistance; and the more complex is the machine, the more likely is this obscurity to arise. Then, as to the second thing supposed, namely, that there were parts which might be spared, without prejudice to the movement of the watch, and that we had proved this by experiment,- - these superfluous parts, even if we were completely assured that they were such, would not vacate the reasoning which we had instituted concerning other parts. The indication of contrivance remained, with respect to them, nearly as it was before. (p.5-6)

Continuing with the analogy of the watch, Paley next argues that one could not explain away the evidence of design even if the watch in hand had, through some exceptional mechanics, been produced by the selfreplication of a parental watch. It matters not, according to Paley, whether any particular entity had been born of similar entities, as this accounts only for its existence and not its complex functional characteristics. Indeed, discovering the watch's capacity to reproduce would only increase an observer's admiration for its remarkable complexity:

No answer is given to this question, by telling us that a preceding watch produced it. There cannot be design without a designer; contrivance without a contriver; order without choice; arrangement, without any thing capable of arranging; subserviency and relation to a purpose, without that which could intend a purpose; means suitable to an end, and executing their office, in accomplishing that end, without the end ever having been contemplated, or the means accommodated to it. Arrangement, disposition of parts, subserviency of means to an end, relation of instruments to a use, imply the presence of intelligence and mind. No one, therefore, can rationally believe, that the insensible, inanimate watch, from which the watch before us issued, was the proper cause of the mechanism we so much admire in it;could be truly said to have constructed the instrument, disposed its parts, assigned their office, determined their order, action, and mutual dependency, combined their several motions into one result, and that also a result connected with the utilities of other beings. All these properties, therefore, are as much unaccounted for, as they were before. (p.11-12)

Thus, Paley argues, no matter how many generations of watches beget watches (or, by obvious implication, organisms produce offspring or cells generate daughter cells), the specific, irreducible, and purposeful arrangement of watches' inner workings can only be attributed to the action of intelligent agency.

\section{The Cosmic Optician}

Having established the connection between watches and watchmakers, Paley begins his third chapter by arguing that the principle applies equally to living organisms and their components - or indeed, more so, given that their degree of adaptive complexity is vastly greater. As he might have argued, human hands more thoroughly evince design than anything crafted by them.

As did many of his predecessors ${ }^{8}$ (and followers), Paley considered eyes to provide a particularly illuminating exemplar of organic design: "there is precisely the same proof that the eye was made for vision, as there is that the telescope was made for assisting it" (p. 18). Paley noted that telescopes and eyes rely on similar optical principles but that in fact vertebrate eyes are much more effective by virtue of their ability to adjust to different distances and brightness, in their well-developed protective features including eyelids and nictitating membranes, and by their capacity to correct for spherical aberration. In fact, he pointed out, telescope designers solved the problem of aberration by adopting features observed in biological lenses. In the absence of a natural explanation for their occurrence, eyes provided one of the best-known cases in support of the design argument. Darwin exposed the fallacy of this conclusion, and the efforts of countless scientists since then have resolved in increasingly fine detail how the various components of eyes are likely to have evolved. ${ }^{9}$

In considering the eyes of different types of animals, Paley noted two critical facts: (1) that eyes differ according to the environment in which they are used to see and (2) that despite these differences, all vertebrate eyes are constructed according to the same basic physical plan. Eyes specialized for sight underwater, on land, or in the dark are not fundamentally different from each other; rather, they are modifications of a general theme: "Thus, in comparing the eyes of different kinds of animals, we see, in their resemblances and distinctions, one general plan laid down, and that plan varied with the varying exigencies to which it is to be applied" (p. 31). Today, this similarity amidst diversity is explained by the fact that all vertebrates share a common ancestor that was possessed of eyes and

\footnotetext{
${ }^{8}$ For example, Paley cites the work of Johann Christophorous Sturm from a century before: "Sturmius held, that the examination of the eye was a cure for atheism" (p.33). Paley himself wrote that "Were there no example in the world, of contrivance, except that of the eye, it would be alone sufficient to support the conclusion which we draw from it, as to the necessity of an intelligent Creator" (p.75).

${ }^{9}$ For two recent special issues of peer-reviewed journals dedicated to eye evolution, see Evolution: Education and Outreach volume 1, issue 4, Oct. 2008 (http://www.springerlink.com/content/m3k441k67q3n/) and Philosophical Transactions of the Royal Society B volume 364, issue 1531, Oct. 19, 2009 (http://rstb.royalsocietypublishing.org/ content/364/1531.toc).
} 
that specializations to different lifestyles have involved descent with modification of this ancestral organ.

The fact that all eyes have evolved through the modification of prior form and the cooption of preexisting components also explains some otherwise puzzling structural complications (not to mention features that are downright maladaptive; see Novella 2008 for several examples). However, through his teleological lens, Paley viewed complexities as further evidence of good design, as with his example of muscles in the eyes of cassowaries:

In the configuration of the muscle which, though placed behind the eye, draws the nictitating membrane over the eye, there is.... marvellous mechanism....The muscle is passed through a loop formed by another muscle: and is there inflected, as if it were round a pulley. This is a peculiarity; and observe the advantage of it. A single muscle with a straight tendon, which is the common muscular form, would have been sufficient, if it had had power to draw far enough. But the contraction, necessary to draw the membrane over the whole eye, required a longer muscle than could lie straight at the bottom of the eye. Therefore, in order to have a greater length in a less compass, the cord of the main muscle makes an angle. This, so far, answers the end; but, still further, it makes an angle, not round a fixed pivot, but round a loop formed by another muscle; which second muscle, whenever it contracts, of course twitches the first muscle at the point of inflection, and thereby assists the action designed by both. (p.37-38; italics in original)

In mammals, the recurrent laryngeal nerve provides a connection between the brain and the larynx, though not a direct one. Instead of taking a direct route, it passes down into the chest, circles under the aorta, and ascends back up to the neck (in giraffes, this nerve is more than 2 meters long; Harrison 1995). Similarly, the mammalian vas deferens connects the testes to the urethra, but not before passing into the pelvic cavity, looping around the urinary bladder and then descending back to complete its circuitous path. Meanwhile, the urethra itself passes directly through the prostate gland, an arrangement that readily engenders urinary difficulties if the prostate becomes swollen. It is only with great effort that arrangements such as these might be characterized as optimizations rather than as simple quirks of evolutionary history ${ }^{10}$ (for additional examples, see Williams 1997; Shubin 2008; Coyne 2009).

But why bother with eyes at all? If the designer is omnipotent, why does the detection of visual information

\footnotetext{
${ }^{10}$ Paley does make an effort to portray the tiny vestigial eyes of moles, which are permanently covered with skin, as an example of good design (pp.273-274).
}

require such a complex arrangement of lenses, receptors, nerves, muscles, and neurons? In Paley's words,

Why make the difficulty in order to surmount it? If to perceive objects by some other mode than that of touch, or objects which lay out of the reach of that sense, were the thing proposed; could not a simple volition of the Creator have communicated the capacity? Why resort to contrivance, where power is omnipotent? Contrivance, by its very definition and nature, is the refuge of imperfection. To have recourse to expedients, implies difficulty, impediment, restraint, defect of power. (p.39)

Thus answers Paley his own rhetorical queries:

...beside reasons of which probably we are ignorant, one answer is this: It is only by the display of contrivance, that the existence, the agency, the wisdom of the Deity, could be testified to his rational creatures. This is the scale by which we ascend to all the knowledge of our Creator which we possess, so far as it depends upon the phenomena, or the works of nature. Take away this, and you take away from us every subject of observation, and ground of reasoning; I mean as our rational faculties are formed at present. Whatever is done, God could have done without the intervention of instruments or means: but it is in the construction of instruments, in the choice and adaptation of means, that a creative intelligence is seen. It is this which constitutes the order and beauty of the universe. God, therefore, has been pleased to prescribe limits to his own power, and to work his end within those limits. (p.40)

According to Paley, the exquisite function of eyes bespeaks the great power of a designer, but the very decision to create eyes reflects an intentional limitation of this power so that humans might understand how eyes came to be. This logic may strike the modern reader as rather tortuous, but it serves to illustrate a very important point: that any explanation for complex organs must account not only for their adaptive characteristics but also their imperfections. Today, this duality can be accounted for by the countervailing influences of adaptive modification and the constraints of genetics, anatomy, and history, but for Paley, the intent of a designer provided the only conceivable answer. As noted, Paley did not consider imperfections to challenge the conclusion that design indicates the work of a designer. It is only if one wishes to defend the infallibility of the designer that one must assume all features of an object to be functional, and optimally so (see pp.56-57). Paley considered nonfunctional aspects of organisms to be "extremely rare," and as is clear from later chapters, he viewed most aspects of the world to be 
optimally designed, but he was careful not to base his argument for the existence of a designer on these secondary considerations. Again, this represents something of a more sophisticated application of the argument from design than is often encountered in contemporary discourse.

\section{Not a Chance}

One of the most obstinate misconceptions about evolutionary theory is that it hypothesizes that eyes and other complex organs arise "by chance." Even under the most charitable assessment, such a view of adaptive evolution must be considered deeply misguided. Whereas genetic mutation is both integral to the process and indeed is random with respect to its effects, natural selection is, by definition, the nonrandom survival and reproduction of individuals. Variation is generated at random, but whether or not it is preserved depends on its effects on survival and reproduction within a given environment ${ }^{11}$ (for reviews, see Gregory 2008, 2009). No serious evolutionary biologist of the past 150 years has suggested that the emergence of complex organs is merely the result of chance.

Writing as he did before Darwin and Wallace proposed the theory of natural selection, it was not possible for Paley to make this error (modern neo-Paleyans, by contrast, do so with remarkable proficiency). In the early 1800 s, chance was not the only suggested alternative to conscious design (McLaughlin 2008), but Paley viewed its refutation as an important part of his argument. Paley (and Darwin) understood that chance plays a role in nature, but that it is incapable of producing adaptive complexity:

What does chance ever do for us? In the human body, for instance, chance, i.e. the operation of causes without design, may produce a wen, a wart, a mole, a pimple, but never an eye. Amongst inanimate substances, a clod, a pebble, a liquid drop might be; but never was a watch, a telescope, an organized body of any kind, answering a valuable purpose by a complicated mechanism, the effect of chance. (p.63)

Modern evolutionary biologists do not part company with Paley on the claim that complex organs must arise through a mechanism other than pure chance. The disagreement is only with his subsequent assertion, that "in no assignable instance hath such a thing existed without intention somewhere" (p.63).

\footnotetext{
${ }^{11}$ This refers specifically to evolution by natural selection. Variation can also be sorted by chance through genetic drift, especially when it is neutral with respect to reproductive success and in small populations, but this mechanism is not responsible for the evolution of complex adaptations.
}

Paley takes his argument against the role of chance a step farther, in the process raising - and summarily rejecting - a possible explanation that exhibits shades of the principle of natural selection. However, his description is of an ancient version of the idea that, as Paley rightly notes, is unworkable in practice. ${ }^{12}$

There is another answer which has the same effect as the resolving of things into chance; which answer would persuade us to believe, that the eye, the animal to which it belongs, every other animal, every plant, indeed every organized body which we see, are only so many out of the possible varieties and combinations of being, which the lapse of infinite ages has brought into existence; that the present world is the relict of that variety: millions of other bodily forms and other species having perished, being by the defect of their constitution incapable of preservation, or of continuance by generation. Now there is no foundation whatever for this conjecture in any thing which we observe in the works of nature; no such experiments are going on at present: no such energy operates, as that which is here supposed, and which should be constantly pushing into existence new varieties of beings. Nor are there any appearances to support an opinion, that every possible combination of vegetable or animal structure has formerly been tried. Multitudes of conformations, both of vegetables and animals, may be conceived capable of existence and succession, which yet do not exist. Perhaps almost as many forms of plants might have been found in the fields, as figures of plants can be delineated upon paper. A countless variety of animals might have existed, which do not exist. Upon the supposition here stated, we should see unicorns and mermaids, sylphs and centaurs, the fancies of painters, and the fables of poets, realized by examples. Or, if it be alleged that these may transgress the limits of possible life and propagation, we might, at least, have nations of human beings without nails upon their fingers, with more or fewer fingers and toes than ten, some with one eye, others with one ear, with one nostril, or without the sense of smelling at all. All these, and a thousand other imaginable varieties, might live and propagate. We may modify any one species many different ways, all consistent with life, and with the actions necessary to preservation, although affording different degrees of conveniency and enjoyment to the animal. And if we carry

\footnotetext{
${ }^{12}$ Similar notions of extreme trial-and-error date back to the ancient Greeks, including Lucretius and Empedocles (Gliboff 2000).
} 
these modifications through the different species which are known to subsist, their number would be incalculable. No reason can be given why, if these deperdits ever existed, they have now disappeared. Yet, if all possible existences have been tried, they must have formed part of the catalogue. (p.63-65)

The problem, of course, is not the notion that great variety may arise by chance and be narrowed by differential survival - this is the basis of natural selection as it is now understood. Rather, the implausibility of Paley's scenario is the scale at which he considered the process. Specifically, he envisioned an unconstrained morphospace in which drastically divergent species continually pop into existence. This lies in stark contrast to Darwin's later emphasis on small-scale variation arising within species and then being sorted generation by generation.

In this context, it is also worth noting Paley's view on extinction-namely that it does not happen. According to Paley, the classification of species into larger taxa would be rendered impossible by widespread extinction. In contrast, extinction was established as a common process in the history of life by Darwin's time, and today it is acknowledged that the overwhelming majority of species that have existed no longer grace the Earth. In fact, the major divisions among extant lineages are now understood to exist precisely because so many ancestors and intermediate forms have perished.

\section{Design and Diversity}

The preceding arguments occupy only the first six of the 27 chapters in Natural Theology. In Chapters 7 through 20, Paley leads the reader on an expedition through the annals of early nineteenth century biological knowledge as he understands it, pausing along the way to admire the elegance of the bones (Chapter 8), muscles (Chapter 9), blood vessels (Chapter 10), and digestive systems (Chapters 7 and 10) of vertebrates, as well as features of insects (Chapter 19) and plants (Chapter 20) which, though less well understood, he also described as bearing the hallmarks of design.

Once again, modern biology does not contradict Paley's enthusiastic exposition of features well-suited to specific functions, only the way in which their origin is explained. Similarly, Paley takes a broad comparative approach that would be at home in modern evolutionary biology were it interpreted from a different perspective. He recognizes that specializations for particular lifestyles reflect modifications of traits shared by many animals. He grasps the unity of underlying body plans. And he notes that though it dissipates among groups living in widely divergent habitats, the similarity does not disappear. Consider the following passages from Chapter 12 on "Comparative Anatomy":

Whenever we find a general plan pursued, yet with such variations in it as are, in each case, required by the particular exigency of the subject to which it is applied, we possess, in such plan and such adaptation, the strongest evidence that can be afforded of intelligence and design; an evidence which most completely excludes every other hypothesis. If the general plan proceeded from any fixed necessity in the nature of things, how could it accommodate itself to the various wants and uses which it had to serve under different circumstances, and on different occasions? (p.211)

Very much of this reasoning is applicable to what has been called Comparative Anatomy. In their general economy, in the outlines of the plan, in the construction as well as offices of their principal parts, there exists between all large terrestrial animals a close resemblance. In all, life is sustained, and the body nourished by nearly the same apparatus. The heart, the lungs, the stomach, the liver, the kidneys, are much alike in all. The same fluid (for no distinction of blood has been observed) circulates through their vessels, and nearly in the same order. The same cause, therefore, whatever that cause was, has been concerned in the origin, has governed the production of these different animal forms.

When we pass on to smaller animals, or to the inhabitants of a different element, the resemblance becomes more distant and more obscure; but still the plan accompanies us. (pp.212-213)

Chapter 13 deals with the opposite subject, namely adaptations ("Peculiar Organizations") that are unique to particular groups: features of the neck of large mammals, the swim bladder of fishes, the fangs of snakes, the pouches of marsupials, the claws of birds, the stomach of camels, the tongue of woodpeckers, and the curved tusks of wild boars. These, like functional traits shared more broadly, also reflect the remarkable fit of species to their environments which Paley takes as strong evidence for their origin by design.

In Chapter 14, Paley lends particular credence to examples of adaptive features that emerge ontogenetically before they are needed, in preparation for use later in life ("Prospective Contrivances"):

I can hardly imagine to myself a more distinguishing mark, and, consequently, a more certain proof of design, than preparation, i.e. the providing of things beforehand, which are not to be used until a 
considerable time afterwards; for this implies a contemplation of the future, which belongs only to intelligence. (p.252)

The teeth of mammals, the milk that nourishes their young, their eyes that develop while still in the darkness of the womb, and their lungs that form before encountering any opportunity to draw a breath - in the absence of knowledge about developmental genetics, these struck Paley as especially weighty examples of foresightful design.

\section{Fitting Together}

Paley does not only rely on individual examples of function to support his position. In addition, he expounds upon the close interaction of parts in service of a specific function. He returns to the analogy of the watch in this capacity at the opening of Chapter 15:

When several different parts contribute to one effect; or, which is the same thing, when an effect is produced by the joint action of different instruments; the fitness of such parts or instruments to one another, for the purpose of producing, by their united action the effect, is what I call relation: and wherever this is observed in the works of nature or of man, it appears to me to carry along with it decisive evidence of understanding, intention, art. In examining, for instance, the several parts of a watch, the spring, the barrel, the chain, the fusee, the balance, the wheels of various sizes, forms, and positions, what is it which would take an observer's attention, as most plainly evincing a construction, directed by thought, deliberation, and contrivance? It is the suitableness of these parts to one another; first, in the succession and order in which they act; and, secondly, with a view to the effect finally produced. (pp. 261-262)

These "relations" are common in nature, and they form a central part of the modern incarnation of the argument from design just as they did two centuries before (albeit recast in terms of the "specified," "irreducibly complex," or "purposeful" arrangements of parts in service of a particular function). Contemporary embodiments of the teleological argument typically appeal to examples from microbiology and biochemistry, but the basic approach is the same as in Paley's discussion of systems involved in feeding, digestion, and excretion. Paley is especially taken by close interactions among independent components (which today are explained as the product of co-evolution):

But relation perhaps is never so striking as when it subsists, not between different parts of the same thing, but between different things. The relation between a lock and a key is more obvious, than it is between different parts of the lock. A bow was designed for an arrow, and an arrow for a bow: and the design is more evident for their being separate implements.

Nor do the works of the Deity want this clearest species of relation. The sexes are manifestly made for each other. They form the grand relation of animated nature; universal, organic, mechanical; subsisting like the clearest relations of art, in different individuals; unequivocal, inexplicable without design.

So much so, that, were every other proof of contrivance in nature dubious or obscure, this alone would be sufficient. The example is complete. Nothing is wanting to the argument. I see no way whatever of getting over it. (pp. 268-270)

According to Paley, the fit of parts is also especially significant "when the defects of one part, or of one organ, are supplied by the structure of another part or of another organ" (p.275), a special case of "relation" that he dubs "compensation." For example, the neck of an elephant is inflexible, but this is compensated for by its dexterous trunk. Paley's ideas of "inconveniency" and "compensation" are recognizable in the modern concept of tradeoffs:

When I speak of an inconveniency, I have a view to a dilemma which frequently occurs in the works of nature, viz. that the peculiarity of structure by which an organ is made to answer one purpose, necessarily unfits it for some other purpose. (pp.278-279)

Not surprisingly, the fit of organisms to their physical environments (e.g., wings for movement in air, fins in water) also provides evidence for design under Paley's view:

We have already considered relation, and under different views; but it was the relation of parts to parts, of the parts of an animal to other parts of the same animal, or of another individual of the same species.

But the bodies of animals hold, in their constitution and properties, a close and important relation to natures altogether external to their own; to inanimate substances, and to the specific qualities of these, e.g. they hold a strict relation to the elements by which they are surrounded. (p.291; italics in original)

Paley also contemplates instincts as an example of "relations" indicative of design. In so doing, he confronts what are now labeled as proximate versus ultimate causes (and, in a long-outdated dichotomy, "nature vs. nurture"). Citing examples of reproductive behaviors - the incubation of eggs by birds, the host specificity of egg laying by 
butterflies, the spawning journeys of salmon-he argues that many behaviors are neither learned nor simple reactions to stimuli but are hardwired by design.

\section{Beyond Biology}

For Paley, evidence of design is not restricted to examples from the living world but also comes from the conditions of the world that make life possible. Chapter 21, dedicated to "The Elements," considers the beneficial properties of air, water, fire, and light. The extent of Paley's teleological reasoning is illustrated with particular clarity in the case of light which, he argues, travels so fast that it might obliterate both eyes and beholders had the designer not provided a safeguard: ${ }^{13}$

Urged by such a velocity, with what force must its particles drive against (I will not say the eye, the tenderest of animal substances, but) every substance, animate or inanimate, which stands in its way! It might seem to be a force sufficient to shatter to atoms the hardest bodies.

How then is this effect, the consequence of such prodigious velocity, guarded against? By a proportionable minuteness of the particles of which light is composed. (p.376)

The properties of the sun, the planets, and the physical laws that govern their motions also point to the action of a designer according to Paley's interpretation. For example, the sun, which provides heat and light, is situated in a convenient central location; the Earth's axis of rotation provides climatological stability; and the laws of gravity are restricted to the miniscule subset of all possible configurations that is compatible with life. Paley held to a particularly strong version of the anthropic principle (not unlike one still invoked by many modern creationists):

That the subsisting law of attraction falls within the limits which utility requires, when these limits bear so small a proportion to the range of possibilities upon which chance might equally have cast it, is not, with any appearance of reason, to be accounted for, by any other cause than a regulation proceeding from a designing mind. But our next proposition carries the matter somewhat further. We say, in the third place, that, out of the different laws which lie within the limits of admissible laws, the best is made choice of; that there are advantages in this particular law which

\footnotetext{
${ }^{13}$ Indeed, he later states that "The eye is made for light, and light for the eye. The eye would be of no use without light, and light perhaps of little without eyes" (p.424).
}

cannot be demonstrated to belong to any other law; and, concerning some of which, it can be demonstrated that they do not belong to any other. (pp. 395-396)

\section{The Nature of the Maker}

Unlike modern proponents of "intelligent design," Paley is totally forthright in his view on the identity of the designer. As he concludes at the close of Chapter 23, "The marks of design are too strong to be gotten over. Design must have had a designer. That designer must have been a person. That person is God." (p.441). From this starting position, Paley proceeds in Chapters 24 through 26 to rally evidence from nature for the omnipotence, omniscience, and benevolence of the Designer. He must, therefore, contend with examples not only confirmatory (e.g., the good fit of organisms to their needs, the capacity for pleasure) but also seemingly contradictory (e.g., death, disease, predation, pain) to such a theological stance. Thus, predation is presented as a form of population control that prevents the potentially disastrous effects of superfecundity (and the application of venom is a particularly merciful method of dispatching prey). Other apparent ills are depicted as being similarly beneficial upon closer inspection. As Paley argues, "It is a happy world after all" (p. 456).

\section{Design Since Darwin}

As Darwin noted, Paley's thesis that the appearance of design must in fact be the outcome of design was refuted by the advent of a workable theory of evolutionary change. Nevertheless, 150 years later, biologists are still awed-but are no longer stunned-by complexity in natural systems. Evolutionary theory provides a means of exploring the origin of complex adaptations using a variety of analytical approaches (e.g., fossil record, genetics, comparative anatomy and physiology, phylogenetics, developmental biology), rather than drawing a conclusion based on the observation of complexity alone. Evolutionary theory, which includes more than adaptive mechanisms, also provides a straightforward explanation for suboptimality, vestigial traits, and wastefulness, including excessive complexity and redundancy where simpler solutions could easily be envisioned.

Interestingly, evolutionary biologists who strongly emphasize adaptive evolution by natural selection (e.g., Dawkins 1986; Williams 1992) - the theory that undermined Paley's central conclusion-more often express positive opinions of Natural Theology than do modern proponents of the argument from design. It is not difficult to see why, as Paley passionately addressed what they see as the most important question in evolutionary biology: the 
origins of complex adaptations. Contemporary design proponents, by contrast, generally attempt to distance themselves from Paley so as not to be seen as simply repackaging a 200-year-old theological argument. The examples may have changed (e.g., from eyes to flagella), but the premise has not.

\section{Concluding Remarks}

Like many of the early works that have had a lasting impact on biological thought, Paley's Natural Theology remains worthy of reading by the current generation of biologists, educators, and students. It presents the argument from design in a clear fashion, unencumbered by the mathematical and biochemical accoutrements with which it recently has been festooned. That arguments very similar to Paley's are now being used in an attempt to undermine the teaching and acceptance of evolutionary science gives Natural Theology continued relevance. From a much more positive point of view, his wonder at the complexity of the natural world, expressed with sincerity and style, is something to which all evolutionary biologists can relate. It is to be hoped that, in time, it will be for this reason alone that Paley's classic treatise retains its significance.

\section{References}

Coyne JA. Why evolution is true. New York: Viking; 2009.

Dawkins, R. The Blind Watchmaker. New York: Penguin Books; 1986.

Fyfe A. Publishing and the classics: Paley's Natural theology and the nineteenth-century scientific canon. Stud Hist Phil Sci. 2002;33:729-51.

Gliboff S. Paley's design argument as an inference to the best explanation, or, Dawkins' dilemma. Stud Hist Phil Biol Biomed Sci. 2000;31:579-97.

Gregory TR. The evolution of complex organs. Evolution: Education and Outreach. 2008;1:358-89.

Gregory TR. Understanding natural selection: essential concepts and common misconceptions. Evolution: Education and Outreach. 2009;2:156-75.

Harrison OFN. The anatomy and physiology of the mammalian larynx. Cambridge: Cambridge University Press; 1995.

McLaughlin P. Reverend Paley's naturalist revival. Stud Hist Phil Biol Biomed Sci. 2008;39:25-37.

Moore R. William Paley, 1743-1805. Reports of the NCSE. 2009;29:26-8.

Novella S. Suboptimal optics: vision problems as scars of evolutionary history. Evolution: Education and Outreach. 2008;1:493-7.

Paley W. Natural Theology, or evidences of the existence and attributes of the deity collected from the appearances of nature. Oxford: Oxford University Press; 1802.

Shubin N. Your inner fish. New York: Pantheon; 2008.

Williams GC. Natural selection: domains, levels, and challenges. Oxford: Oxford University Press; 1992.

Williams GC. The pony fish's glow. New York: Basic Books; 1997. 